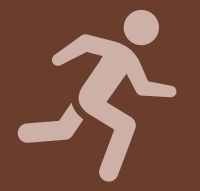

\title{
sports
}

an Open Access Journal by MDPI

Indexed in: PubMed

CITESCORE

4.5

Academic Open Access Publishing 


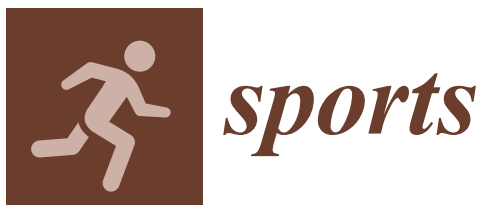

an Open Access Journal by MDPI

Editor-in-Chief

Prof. Dr. Eling Douwe De Bruin

\begin{abstract}
Message from the Editor-in-Chief
Sports (ISSN 2075-4663) is a peer-reviewed scientific journal that publishes original articles, critical reviews, research notes and short communications in the interdisciplinary area of sport sciences and public health. It links several scientific disciplines in an integrated fashion, to address critical issues related to sport sciences and public health. The journal presents diverse original articles, including systematic and narrative reviews, cohort and case control studies, innovative randomized trials, and formative research using qualitative and quantitative methods with the aim to provide information for researchers to plan intervention programs. It addresses diverse public health, physical activity and exercise science topics.
\end{abstract}

\section{Author Benefits}

Open Access Unlimited and free access for readers

C No Copyright Constraints Retain copyright of your work and free use of your article

\section{\&. Thorough Peer-Review}

S Discounts on Article Processing Charges (APC) If you belong to an institute that participates with the MDPI Institutional Open Access Program

$\square$ No Space Constraints, No Extra Space or Color Charges No restriction on the length of the papers, number of figures or colors 


\section{Aims and Scope}

This international journal covers a broad spectrum of important topics which are relevant to sport sciences and public health. It provides comprehensive and unique information with a worldwide readership. Emphasizing an holistic approach, the journal serves as a comprehensive and multidisciplinary platform, addressing important issues. A large number of eminent professors and scientists from all over the world serve as editorial board members and guest reviewers for the journal.

The scope of Sports includes:

Anatomy

Biochemistry

Biomechanics

Clinical aspects of exercise

Ergonomics

Kinanthropometry

Management of sports injuries

Psychology

Sociology

Sports medicine and sciences

Sports nutrition

Other interdisciplinary perspectives

\section{Editorial Office}

Sports Editorial Office sports@mdpi.com MDPI, St. Alban-Anlage 66 4052 Basel, Switzerland Tel: +41 616837734 www.mdpi.com mdpi.com/journal/sports 


\section{GSPA}

The Association of Learned \& Profession Society Publishers

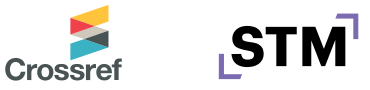

Society for Scholarly Publishing
$|\mathbf{C}| \mathbf{O}|\mathbf{P}| \mathbf{E}$

SPARC*

Europe

\section{DOAJ}

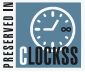

ORCID

\section{Follow}

f facebook.com/MDPIOpenAccessPublishing

twitter.com/MDPIOpenAccess

in linkedin.com/company/mdpi

(O) instagram.com/mdpiopenaccess

$\boldsymbol{6}^{\text {") }}$ weibo.com/mdpicn

Wechat:MDPI-China

\section{Subscribe}

blog.mdpi.com 